\title{
Thermal Characterization In Vitro of Human Nail: Photoacoustic Study of the Aging Process
}

\author{
Daniele Toniolo Dias ${ }^{\star 1,2}$, Alysson Steimacher ${ }^{1}$, Antonio Carlos Bento ${ }^{1}$, Antonio Medina Neto ${ }^{1}$ and \\ Mauro Luciano Baesso ${ }^{1}$ \\ ${ }^{1}$ Departamento de Física, Universidade Estadual de Maringá, Maringá, PR, Brazil \\ ${ }^{2}$ Departamento de Física do Estado Sólido, Instituto de Física, Universidade Federal da Bahia, Salvador, BA, Brazil \\ Received 4 December 2006; accepted 11 January 2007; DOI: 10.1111/j.1751-1097.2007.00074.x
}

\begin{abstract}
In the present work, the rear photoacoustic signal technique is used to determine thermal properties of human nails. The aging process of the human nail is analyzed through its thermal diffusivity and specific heat and using these results, thermal conductivity and thermal effusivity is determined. The study in vitro of this natural polymer showed a minimum for thermal properties to age about 20 years and an increase and possible saturation of them for ages over 50 years. The minimum value found for thermal diffusivity was close to $10 \times 10^{-4} \mathrm{~cm}^{2} \mathrm{~s}^{-1}$ with saturation near $18 \times 10^{-4} \mathrm{~cm}^{2} \mathrm{~s}^{-1}$. Thermal conductivity and effusivity presents the same behavior.
\end{abstract}

\section{INTRODUCTION}

The human nail is one of the interfaces between the body and the environment, and it plays an important role in the defense of the organism. Its natural polymers present a layered structure and it is important not only in the esthetic aspect but also in the identification of diseases that can be observed through its physical aspect $(1,2)$. It is recognized that both fingernails and bones contain a crucial bonding substance, which helps give them strength and nowadays it is reported that simple tests using lasers can detect low levels of bone disease osteoporosis simply by scanning a patient's fingernail. The insights pointed out that fingernails could be useful in diagnosing this disease, which may come up when a physician notices floppy nails in the patients (3). As much in practical dermatological terms as in practical generality, the illness of the nails constitutes common complaint that demands more important and detailed study of their physical properties. In vitro and in vivo biomaterial properties of many organs (or its parts) and tissue are discussed and tabulated by Bowman et al. (4) in the Annual Review of Biophysics and Bioengineering. This review reports on properties of thermal conductivities and diffusivities of parts of bovines, cats, chicken, pigs and human. Although this review presents many thermal properties for human tissues and some human organs, the human nails have not been evaluated to date.

Recently, Sowa et al. (5) studied ex vivo human nails under antifungal therapy, using infrared spectroscopy and pointed

*Corresponding author email: daniele@ufba.br (Daniele Toniolo Dias) (c) 2007 The Authors. Journal Compilation. The American Society of Photobiology 0031-8655/07 out the need of depth profiling analysis. This analysis considers thermal parameters such as thermal diffusion coefficient. From the finding of this work one may realize that nails' thermal properties were not found in the literature $(4,6-9)$ and that thermal diffusivity is a fundamental parameter for such depth profile analysis (10). Farren et al. (6) have examined the fracture properties and mechanical design of human fingernails. Cutting tests showed that the energy to cut nails transversely is approximately $3 \mathrm{~kJ} \mathrm{~m}^{-2}$, half that needed to cut them longitudinally $\left(\approx 6 \mathrm{~kJ} \mathrm{~m}^{-2}\right)$. Therefore, when nails were bent, cracks were always diverted transversely, parallel to the free edge of the nail. This is another important fact related to some anisotropy, which may be found in thermal properties as well. Geyer et al. (1) studying the linear nail growth for treating diseases of the nail observed that in diseases affecting the nails, an abnormal rate of growth may contribute to nail dystrophy. Bhavaraju et al. (7) proposed an experimental technique to measure the directional thermal conductivity and thermal diffusivity of materials. In addition, in swine tissue an average thermal conductivity from $61 \times 10^{-4}$ (in vivo) to $50 \times 10^{-4} \mathrm{~J} \mathrm{~s}^{-1} \mathrm{~cm}^{-1} \mathrm{~K}^{-1}$ (in vitro) and average values for diffusivity ranging from $21 \times 10^{-4}$ (in vivo) to $17 \times 10^{-4}$ (in vitro) $\mathrm{cm}^{2} \mathrm{~s}^{-1}$ were found (7). Shitzer et al. (2) performing simultaneous measurements of middle finger-tip temperatures and blood perfusion rates in a cold environment showed that average finger-tip temperatures $\left(11.8-15.5^{\circ} \mathrm{C}\right)$ varied much less than other subjects of analysis such as the average blood perfusion rates $\left(2.8-17.0 \mathrm{~mL}_{\mathrm{b}} \mathrm{mL}_{\mathrm{t}}^{-1} \mathrm{~h}^{-1}\right)$. Repka et al. (3) have discussed a study in vitro analyzing human nails under antifungal therapy. The paper presents the properties of holtmelt extruded films containing ketoconazole, the influence of nail etching on film bioadhesion and drug permeability for the assessment of topical onychomycosis therapies. Data from this study have indicated that nail samples treated with an etchant demonstrated a significant increase in both film bioadhesion and drug permeability.

The optical and thermal characterization of biological materials has attracted the attention of researchers in the photothermal field and there are several studies based on the analysis of the skin under light or laser illumination in vitro and in vivo (11). For example, cream residence time (12), water-keratin interactions in stratum corneum (13), ethnic dependence of melanin content in human skin (14) and thermal diffusivity as well as laser-induced effects in the epidermis and the stratum corneum $(15,16)$. Some exploit 
thermal-generated effects and others the optical absorption changes in the skin under perfusion of some substances, cream rubbing and so on. The use of photoacoustic effect arose after Rosencwaig introduced the first theory for this effect in solid materials (17) and since then, many authors have used this effect to develop alternative methodology. Among them is the proposal $(18,19)$ of a minimum volume cell applied to spectroscopic and thermal properties measurements based on the rear illumination instead of that originally proposed by Rosencwaig.

Thus, in this paper the rear photoacoustic signal technique is applied owing the measurement the thermal diffusivity of the human nail for people of different ages. Furthermore, as a complementary experiment, through the method of thermal relaxation (20), the specific heat of the nail was determined for a complete analysis of thermal properties evaluation with age.

\section{MATERIALS AND METHODS}

Materials. The human nail presents in the composition three main layers (5). A hard and more external layer called the dorsal layer. An intermediate layer, more flexible and the ventral layer, composed of cellular layers. This structure is a result of the cutaneous production of compacted and hardened queratin, named oniquine, that is composed of proteins, sulfur, cystine, argine, water (7-16\%), calcium and iron. In Fig. 1a the chemical structure of queratin, the main protein (natural polymer) of the nail is observed. The top bold portion of this structure is known as $\boldsymbol{\alpha}$-aminoacids. Proteins like queratin are known as polypeptides (21); have a defined order relating to the amino acid groups forming the natural polymer. Looking at the other part of the chemical structure of queratin (Fig. 1a), the radical determines the properties of the protein. Differently of the silk (derived from glycine and alanine), queratin contains not only a vast variety of amino acid but also a particularly great amount of cystine. As a result the polypeptides chains are on (disulfur linking) in such way that queratin is a polypeptide with interconnections. It shows a reasonable extensibility, particularly in high temperatures and in contact with humidity. Probably, under these conditions, some of the disulfur links are broken. Based on the above character of fingernail, it is clear that physical properties are very important for such a complex organ. The samples of human nails used for the measures of thermal properties were of seven healthy volunteers (range 16-53 years; 86\% constitutively light white skin; male $=30 \%$ ) therefore, transparent, smooth and soft. Test samples were taken from at least three fingernails to get better control of the possible dispersion. The nail was cut and files for the withdrawal of the internal surface layer (Fig. 1b), which resulted in an average thickness $(260 \pm 7) \times 10^{-6} \mathrm{~m}$ and diameter about $6 \mathrm{~mm}$, enough for photoacoustic (PA) experiment with an open cell (Fig. 2).
The nail was painted in black to guarantee the opacity of the sample, and the thickness was measured with a digital micrometer (Digimatic Mytutoyo) having an accuracy of $1 \mu \mathrm{m}$.

Photoacoustic signal. The PA cell consists of a narrow column of gas having a minimal volume and in the cylindrical form. The configuration uses an acrylic-made cell body having dual side illumination possibilities but only the rear illumination was used here. The gas column is closed from one side with a sapphire window and the other side is closed with the nail sample itself. The chamber leads to a double way duct, one that binds to the chamber of the Sennheiser microphone and the other that binds to a removable screw used for safety during replacement of samples and in order to guarantee the same chamber pressure for all sample measurements.

The generation of the photoacoustic signal is mainly from the expansion and the contraction of the narrow adjacent layer of gas in contact with the warm surface of the sample, predicted and well imposed by Rosencwaig-Gersho (RG) thermal piston model (17). For a dual side illumination fashion, a modified RG model is used for a rear illumination using a condition that assures strong absorption near the sample surface, thus the thermal diffusion model leads us to the pressure variation in the chamber as (18):

$$
P(\omega)=\frac{\gamma P_{0} I_{0}\left(\alpha_{\mathrm{g}} \alpha_{\mathrm{s}}\right)^{1 / 2}}{\ell_{\mathrm{g}} T_{0} k_{\mathrm{s}} \omega} \frac{\mathrm{e}^{j\left(\omega t-\frac{\pi}{2}\right)}}{\sinh \left(\sigma_{\mathrm{s}} \ell_{\mathrm{s}}\right)}
$$

$P(\omega)$ is the chamber pressure and it is a function of modulation of light $(\omega=2 \pi \mathrm{f})$ for an opaque material. In (Eq. 1) $\gamma=c_{\mathrm{p}} / c_{\mathrm{v}}$ is the specific heat ratio; $P_{0}$ and $T_{0}$ are the ambient pressure and temperature; $I_{0}$ the flux of light monochromatic incident; $k_{\mathrm{i}}$ and $\alpha_{\mathrm{i}}$ are the thermal conductivity and diffusivity, respectively; $i=$ "g" (gas) and $i=$ "s" (sample); the complex parameter $\sigma_{\mathrm{i}}=(1+j) a_{\mathrm{i}}$ is frequency dependent. The limiting cases are given for two situations: thermally thin $l_{\mathrm{s}} a_{\mathrm{s}}<<1$, where pressure is dependent on $f^{-3 / 2}$, and for thermally thick $l_{\mathrm{s}} a_{\mathrm{s}}>>1$, with signal decaying exponentially with frequency as

$$
S \propto\left(\frac{c t e}{f}\right) \exp (-b \sqrt{f})
$$

In the first situation, calibration is generally needed for the electret microphones as they are not flat in low frequency range and the response is obtained. For a thermally thick situation, the thermal diffusivity can be calculated from the exponential dependence of the signal that allows one to fit the parameter $b=\sqrt{\pi \ell^{2} / \alpha_{s}}$ and so forth the thermal diffusivity as thickness is known.

For this experiment the Sennheiser electret microphone with $10 \mathrm{mVPa}^{-1}$ of sensibility was used for supporting the nail piece and this sample was illuminated in the external surface (see Fig. 1b) with an Omnichrome $\mathrm{HeCd}$ laser $(75 \mathrm{~mW}$ at $442 \mathrm{~nm}$ ) in several runs. The modulation beam was made with a Stanford mechanical Chopper SR540 and the signal detection with a Stanford Lock-in amplifier SR830.

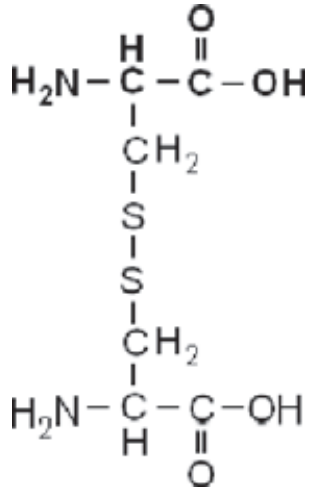

(a)

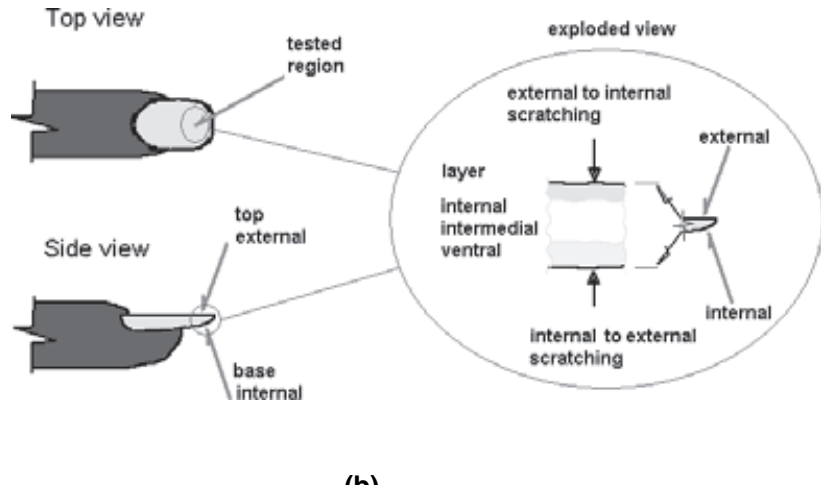

(b)

Figure 1. (a) Chemical composition of a common protein: queratin. (b) Internal and external surface layer of the nail. 


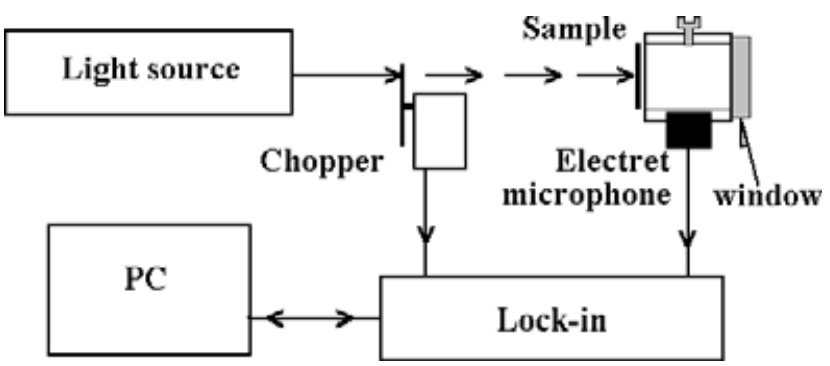

Figure 2. Experimental setup for rear-illumination PA experiment in nail.

\section{RESULTS AND DISCUSSION}

\section{Thermal diffusivity}

The measurements for the thermal diffusivity were performed in the range from 6 to $100 \mathrm{~Hz}$ as this fits very well the experimental condition needed for this technique when rear illumination is used. Figure 3 shows typical signal decay for nail sample as a function of chopping frequency. The logarithm graphic shows that the model is valid in the range of frequencies used here, behaving as a thermally thick sample.

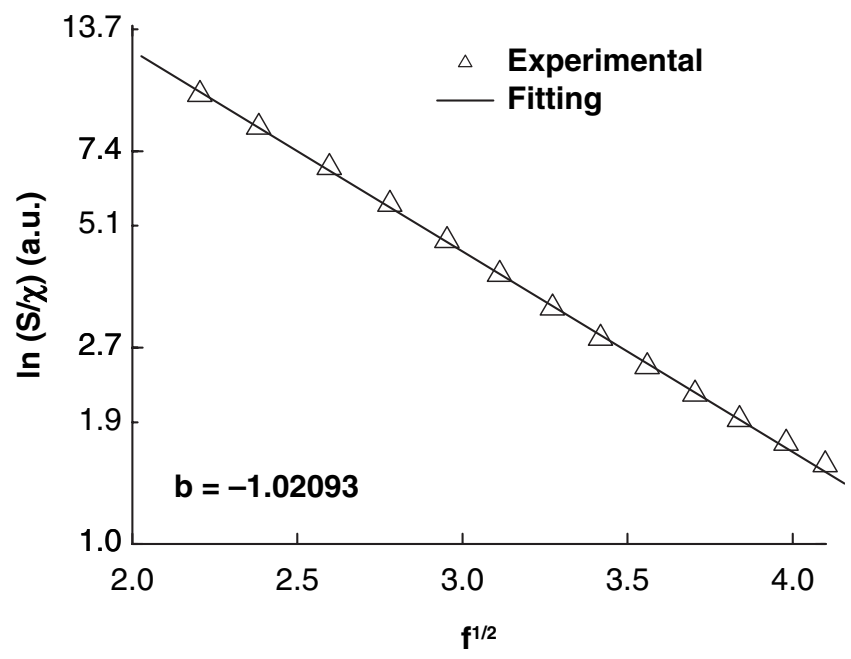

Figure 3. Rear-illumination PA typical linear plot of photoacoustic signal $\times f^{1 / 2}$.
After fitting the photoacoustic signal dependence, which supplies parameter $b$, the thermal diffusivity is calculated. In previous studies (22) we find values of (7.6110.8) $\times 10^{-4} \mathrm{~cm}^{2} \mathrm{~s}^{-1}$, getting an average thermal diffusivity for the nail (age 20 years) $\alpha \sim(9 \pm 2) \times 10^{-4} \mathrm{~cm}^{2} \mathrm{~s}^{-1}$. This value is comparable to that of the human skin $[\sim 13.6 \times$ $10^{-4} \mathrm{~cm}^{2} \mathrm{~s}^{-1}$, calculated from two different parameters, conductivity and thermal inertia, see Bowman et al. (4), p. 60 and to that of synthetic polymeric materials $\left(\sim 11 \times 10^{-4} \mathrm{~cm}^{2} \mathrm{~s}^{-1}\right.$, typical for low-density polyethylene (LDPE) (18) and polyethylene terephthalate (PET) (23)]. As far as we are aware, this is the first time that one obtains the thermal diffusivity for a human nail using direct measurement of a thermal coefficient of diffusion.

In one-second stage, the values for thermal diffusivity as a function of the age were determined. The dependence of the signal with frequency presents a peculiar slope for each sample but all were similar to that shown in Fig. 3. The thickness $\left(l_{\mathrm{s}}\right)$, thermal diffusivity $(\alpha)$, the mean value of the specific heat $\left(c_{\mathrm{p}}\right)$, conductivity $(k)$ and thermal effusivity $(e)$ of the samples are presented in Table 1.

In Fig. 4, the thermal diffusivity evolution with the age is observed pointing to a nonlinear increase $\left(\delta \alpha / \alpha_{0} \sim 63 \%\right)$ with the age, with a possible stabilization for higher ages (53 years measured limit). Perhaps one of the reasons of this fact is the loss of proteins (as queratin) with aging. The variation in the results for young individuals can be caused by the process of formation and growth (of the proper aging). The average growth rate for nails is $0.1 \mathrm{~mm}$ each day but the exact rate of nail growth depends on numerous factors including the age and sex of the individual. Fingernails generally grow faster in young people, which might be related to the minimum observed in Fig. 4, near 20 years. This is probably due to the actual stage of protein consolidation in queratin.

Although the set of samples have different ethnical sources, the only influentially factor in the thermal diffusivity is age (or perhaps losses of protein), as the density of mass, measured using the Picnometer method (graduated $10 \mathrm{ml}$ ), were found constant for three evaluated age bands (20, 32 and 52 years) $\rho \sim(1.27 \pm 0.01) \mathrm{g} \mathrm{cm}^{-3}$.

\section{Specific heat}

The specific heat of the human nail was measured at room temperature using the non-adiabatic method of thermal relaxation (21). It is derived in the same way by fitting data

Table 1. Thermal properties* of human nails calculated using $\rho_{\text {(mean) }} \sim(1.27 \pm 0.01) \mathrm{g} \mathrm{cm}^{-3}$ and $c_{\mathrm{p}(\text { mean })} \sim(1.68 \pm 0.04)\left(\mathrm{J} \mathrm{g}^{-1} \mathrm{~K}^{-1}\right)$.

\begin{tabular}{lccccc}
\hline $\begin{array}{l}\text { Sample } \\
\text { (nail) }\end{array}$ & $\begin{array}{c}\text { Age } \\
\text { (years) }\end{array}$ & $\begin{array}{c}l_{\mathrm{s}} \\
(\mu \mathrm{m})\end{array}$ & $\begin{array}{c}\alpha \\
\left(10^{-4} \mathrm{~cm}^{2} \mathrm{~s}^{-1}\right)\end{array}$ & $\begin{array}{c}k=\alpha \rho c_{\mathrm{p}} \\
\left(10^{-4} \mathrm{~J} \mathrm{~s}^{-1} \mathrm{~cm}^{-1} \mathrm{~K}^{-1}\right)\end{array}$ & $\begin{array}{c}e=k \alpha^{-1 / 2} \\
\left(10^{-4} \mathrm{~J} \mathrm{~s}^{-1 / 2} \mathrm{~cm}^{-2} \mathrm{~K}^{-1}\right)\end{array}$ \\
\hline 1 & 16 & 285 & $11.3 \pm 0.8$ & $24.1 \pm 0.8$ & $7.2 \pm 0.9$ \\
2 & 20 & 135 & $10.0 \pm 0.9$ & $21.3 \pm 0.9$ & $6.7 \pm 0.9$ \\
3 & 22 & 180 & $11.6 \pm 0.9$ & $24.8 \pm 0.9$ & $7.3 \pm 0.9$ \\
4 & 23 & 212 & $10.0 \pm 0.4$ & $27.3 \pm 0.5$ & $7.7 \pm 0.7$ \\
5 & 30 & 290 & $13.0 \pm 0.1$ & $34.8 \pm 0.2$ & $8.6 \pm 0.4$ \\
6 & 35 & 307 & $16.3 \pm 0.1$ & $38.6 \pm 0.2$ & $9.1 \pm 0.4$ \\
7 & 45 & 300 & $18.1 \pm 0.1$ & $40.3 \pm 0.9$ & $9.3 \pm 0.9$ \\
8 & 53 & 344 & $18.9 \pm 0.9$ & & 0.9 \\
\hline
\end{tabular}

\footnotetext{
${ }^{*} \alpha$ and $c_{\mathrm{p}}$ were measured by photothermal methods and $k$ and $e$ were calculated from $\alpha, \rho$ and $c_{\mathrm{p}}$.
} 


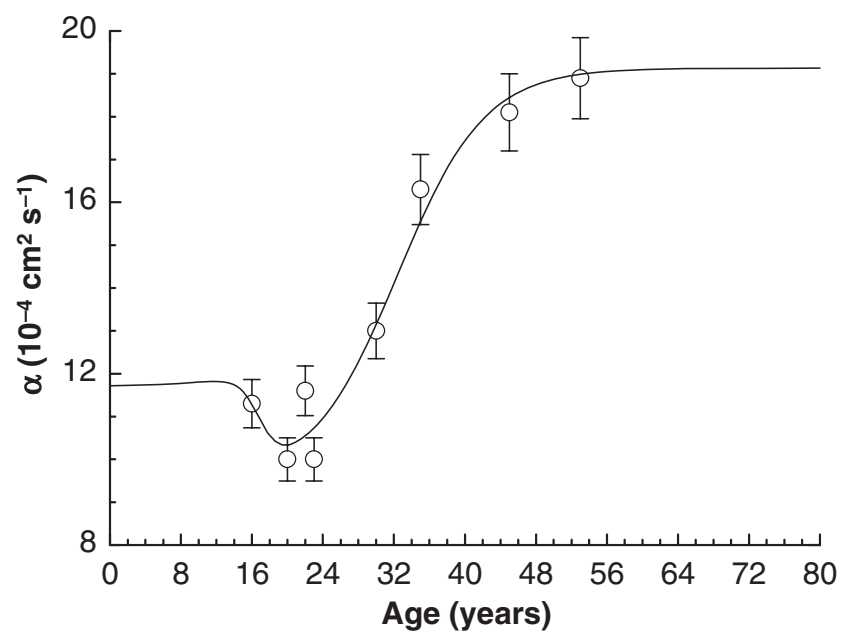

Figure 4. Thermal diffusivity $\times$ age.

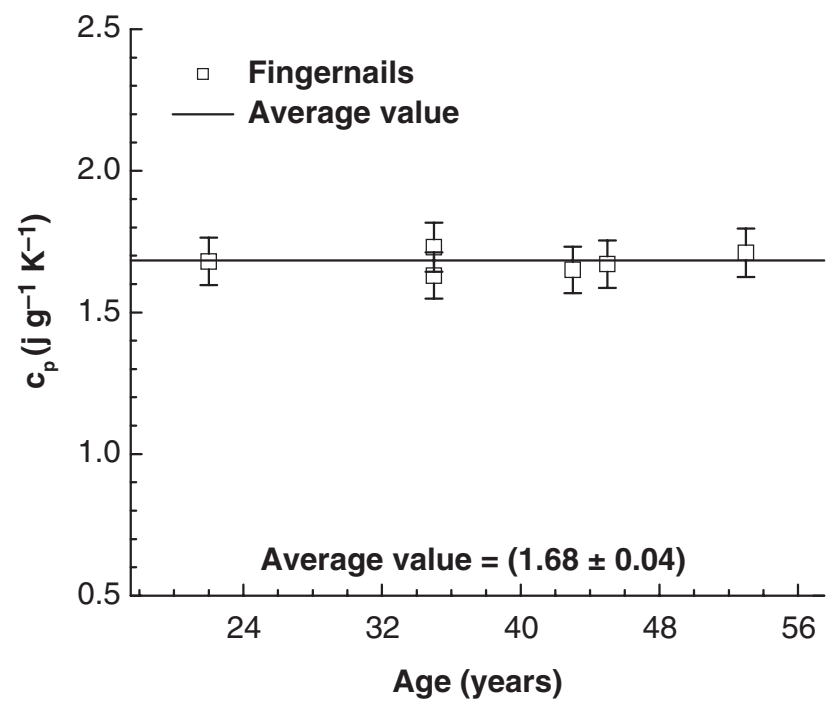

Figure 5. Heat specific for human nail.

to $\tau$ and to $\Delta T_{\max }$. The results can be observed in Fig. 5 , for all six sample ages $(22,35,43,45$ and 53 years old). The value calculated varied from 1.5 to 1.7 with an averaged value $\mathrm{cp}$ $(1.68 \pm 0.04) \mathrm{J} \mathrm{g}^{-1} \mathrm{~K}^{-1}$. This result would be expected as the morphologic structure does affect so much this parameter from sample to sample, as it is expected for thermal parameter.

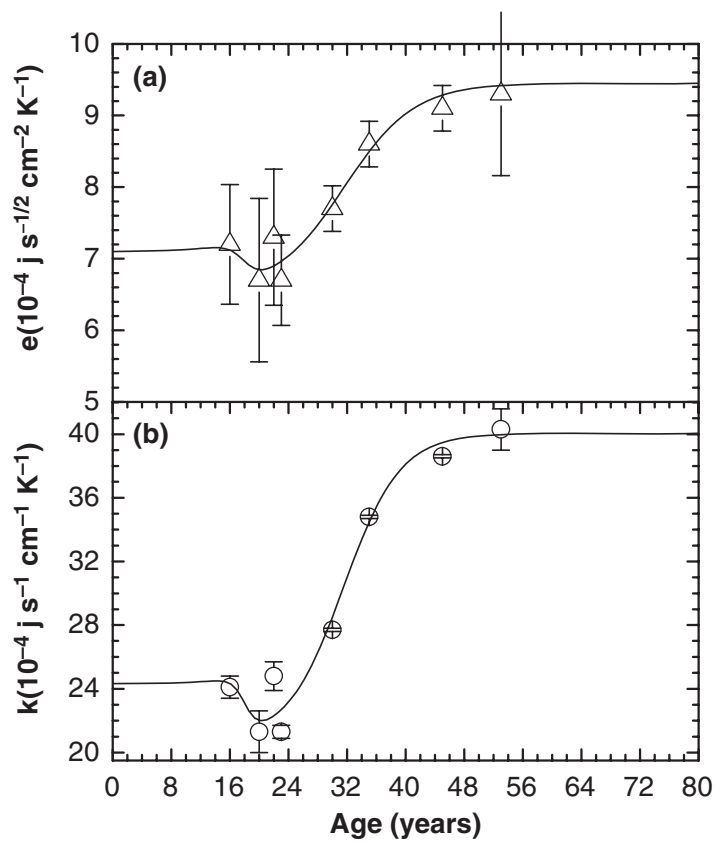

Figure 6. Thermal properties of the human nail: (a) thermal effusivity and (b) thermal conductivity.

\section{Thermal conductivity and effusivity}

The thermal conductivity and the effusivity of the samples were calculated using the relations $\alpha=\left(k / \rho c_{\mathrm{p}}\right)$ and $e=\left(k \rho c_{\mathrm{p}}\right)^{1 / 2}$. These results are observed in Table 1. In Fig. 6 is observed the trend for thermal effusivity (Fig. 6a) and thermal conductivity (Fig. 6b). One can observe that the thermal effusivity that depends on $(k)^{1 / 2}$ presents a small increase $\left(\delta e / e_{0} \sim 33 \%\right)$ with the aging of the human nail, suggesting that the heat flow due to the contact does not present significant variations with age. This parameter is very representative of heat flow in between layers in contact, for which a good thermal matching is needed. On the other hand, the thermal conductivity that depends on diffusivity $\alpha$ presents similar behavior to that of Fig. 4 , which increases $\left(\delta k / k_{0} \sim\right.$ $65 \%$ ) with age, the conduction of heat also has a minimum near age 20 years and increases with aging reaching saturation after age 50 years.

\section{Thermal evolution}

The discussion above can be better supported by means of the evolution shown in Figs. 4 and 6. The solid curves depicted in

Table 2. Analysis of the evolution of $\alpha, e$ and $k$ with age for fingernails using a biphasic pharmacology function.

\begin{tabular}{|c|c|c|c|c|c|c|c|c|}
\hline \multirow[b]{2}{*}{ Properties } & \multirow{2}{*}{$\frac{\text { Early age extrapolation }}{\mathrm{d} 1}$} & \multirow{2}{*}{$\frac{\text { Minimum }}{\mathrm{dm}}$} & \multirow{2}{*}{$\frac{\text { Saturation }}{\mathrm{ds}}$} & \multicolumn{2}{|c|}{ Inflexion ages } & \multicolumn{2}{|c|}{$\begin{array}{l}\text { Slopes at } \\
\text { inflection }\end{array}$} & \multirow{2}{*}{$\frac{\text { Age at minimum* }}{(\text { years })}$} \\
\hline & & & & i1 & $\mathrm{i} 2$ & $\mathrm{t} 1$ & $\mathrm{t} 2$ & \\
\hline$\alpha$ & 11.71 & 9.48 & 19.13 & 16.78 & 32.41 & 2.71 & 11.31 & 19.87 \\
\hline$e$ & 7.09 & 6.54 & 9.45 & 17.87 & 31.60 & 2.50 & 11.00 & 20.59 \\
\hline$k$ & 24.32 & 20.76 & 40.05 & 18.00 & 32.54 & 2.00 & 8.90 & 20.14 \\
\hline
\end{tabular}

*Obtained from first derivative of solid line fitting (Eq. 3) looking up at the minimum point of Figs. 4, 6a,b. 
these figures are representative of guiding the thermal parameter evolution with age and were obtained fitting each property to the pharmacology function:

$$
\mathrm{Ph}(\text { age })=\left(\mathrm{dm}+\frac{(\mathrm{d} 1-\mathrm{dm})}{1+10^{(\text {age }-\mathrm{i} 1 / t 1)}}+\frac{(\mathrm{ds}-\mathrm{dm})}{1+10^{(\mathrm{i} 2-\text { age } / t 2)}}\right)
$$

The parameters of this biphasic pharmacology function $\mathrm{dm}$, $\mathrm{d} 1, \mathrm{ds}, \mathrm{i} 1, \mathrm{i} 2, \mathrm{t} 1$ and $\mathrm{t} 2$ are defined in the columns of Table 2. The first inflection point is found near the age of 16 years and the second at age of 32 years. Data in the rightmost column of Table 2 are from the first derivative of (Eq. 3), which supplied the age at the minima fitted, $\mathrm{dm}$. The most important for instance might be the existence of a minimum for ages close to 20 years and the saturation trends for all thermal properties for ages above 32 years.

Finally, by means of the determination of the thermal diffusivity, the thermal diffusion length of the human nail was determined to be of the order $38 \mu \mathrm{m}$. These results were used in the spectroscopic evaluation of antifungal agent's penetration into human fingernails (24), which constitute a very important study for the development of new therapeutic formulations.

\section{CONCLUSION}

Through the rear photoacoustic signal technique, the value for the thermal diffusivity of the human nail was measured as a function of age. The results showed an increase and possible saturation of thermal diffusivity with age. The average value for $\alpha$ was $\sim 13.7 \times 10^{-4} \mathrm{~cm}^{2} \mathrm{~s}^{-1}$, which agrees with values normally found for other similar human tissue and polymerlike materials. We believe that the value found here can be very worthy when tabulated as it may be used for any drugs delivery studies that need to take into account the heat propagation as well as to know or calculate the depth profiling of therapeutical substances applied to fingernails.

Acknowledgements - The authors thank the Brazilian agencies CNPq, Capes and Fundação Araucária - Paraná for the partial support of this work and Stiefel Brazil Inc. for grants to part of this work.

\section{REFERENCES}

1. Geyer, A. S., N. Onumah, H. Uyttendaele and R. K. Scher (2004) Modulation of linear nail growth to treat diseases of the nail. J. Am. Acad. Dermatol. 50, 229-234.

2. Shitzer, A., L. A. Stroschein, M. W. Sharp, R. R. Gonzalez and K. B. Pandolf (1997) Simultaneous measurements of finger-tip temperatures and blood perfusion rates in a cold environment. J. Therm. Biol. 22, 159-167.

3. Repka, M. A., P. K. Mididoddi and S. P. Stodghill (2004) Influence of human nail etching for the assessment of topical onychomycosis therapies. Int. J. Pharm. 282, 95-106.
4. Bowman, H. F., F. G. Cravalho and M. Woods (1975) Theory, measurement, and application of thermal properties of biomaterials. Annu. Rev. Biophys. Bioeng. 4, 43-80.

5. Sowa, M. G., J. Wang, C. P. Schultz, M. K. Ahmed and H. H. Mantsch (1995) Infrared spectroscopic investigation of vivo and ex vivo human nails. Vib. Spectrosc. 10, 49-56.

6. Farren, L., S. Shayler and R. Ennos (2004) The fracture properties and mechanical design of human fingernails. J. Exp. Biol. 207, 735-741.

7. Bhavaraju, N. C., H. Cao, D. Y. Yuan, J. W. Valvano and J. G. Welster (2001) Measurement of directional thermal properties of biomaterials. IEEE Trans. Biomed. Eng. 48, 261-267.

8. Xiao, P., J. A. Cowen and R. E. Imhof (2001) In vivo transdermal drug diffusion depth profiling - A new approach to opto-thermal signal analysis. Anal. Sci. 17, S349-S352.

9. Sehn, E., K. C. Silva, V. S. Retuci, A. N. Medina, A. C. Bento and M. L. Baesso (2003) Photoacoustic spectroscopy to evaluate the penetration of sunscreens into human skin in vivo: A statistic treatment. Rev. Sci. Instrum. 74, 758-760.

10. Pines, E. (1978) New technique to assess sunscreen effectiveness. J. Soc. Cosmet. Chem. 29, 559-564.

11. Snook, R. D., R. D. Lowe and M. L. Baesso (1998) Photothermal spectrometry for membrane and interfacial region studies. Analyst 123, 587-593.

12. Guo, X., L. I. Ciortea, R. P. Chilcott, R. E. Imhof and P. Xiao (2001) Opto-thermal measurement of barrier cream residence time on skin in-vivo. Anal. Sci. 17, S346-S348.

13. Guo, X., R. E. Imhof and J. Rigal (2001) Spectroscopic study of water-keratin interactions in stratum corneum. Anal. Sci. 17, S342-S345.

14. Alaluf, S., D. Atkins, K. Barret, M. Blount, N. Carter and A. Heath (2002) Ethnic variation in melanin content and composition in photoexposed and photoprotected human skin. Pigment Cell Res. 15, 112-118.

15. Brown, S. M., M. L. Baesso, J. Shen and R. D. Snook (1993) Thermal-diffusivity of skin measured by 2 photothermal techniques. Anal. Chem. Acta 282, 711-719.

16. Baesso, M. L., J. Shen and R. D. Snook (1994) Laser-induced photoacoustic signal phase study of stratum corneum and epidermis. Analyst 119, 561-562.

17. Rosencwaig, A. and A. Gersho (1976) Theory of the photoacoustic effect with solids. J. Appl. Phys. 47, 64-69.

18. Perondi, L. F. and L. C. M. Miranda (1987) Minimal-volume photoacoustic cell measurement of thermal diffusivity: effect of the thermoelastic sample bending. J. Appl. Phys. 62, 2955-2959.

19. da Silva, M. D., I. N. Bandeira and L. C. M. Miranda (1987) Open-cell photoacoustic radiation detector. J. Phys. E Sci. Instrum. 20, 1476-1478.

20. Medina, A. N., A. M. F. Caldeira, A. C. Bento, M. L. Baesso, J. A. A. Sampaio, T. Catunda and F. G. Gandra (2002) Thermal relaxation method to determine the specific heat of optical glasses. J. Non-Cryst. Sol. 304, 299-305.

21. Alfrey, T. and E. F. Gurnee (1967) Organic Polymers. PrenticeHall, Englewood Cliffs, NJ.

22. Dias, D. T., L. E. R. Nuglish, E. Sehn, M. L. Baesso, A. N. Medina and A. C. Bento (2005) Human nail thermal diffusivity obtained using the open photoacoustic cell technique. J. Physique IV, 125, 657-660.

23. Korpiun, P., B. Merté, G. Fritsch, R. Tilgner and E. Lüscher (1983) Photoacoustic method for the measurement of the thermal diffusivity of drawn foils. Colloid Polym. Sci. 261, 312-318.

24. Nuglisch, L. E. R., D. T. Dias, E. Seh, A. C. Bento, M. L. Baesso, S. T. S. Santos and M. Y. Fushimi (2005) Photoacoustic spectroscopy to evaluate the penetration of two antifungal agents through the human nail. J. Phys. IV Colloq. 125, 631-633. 